
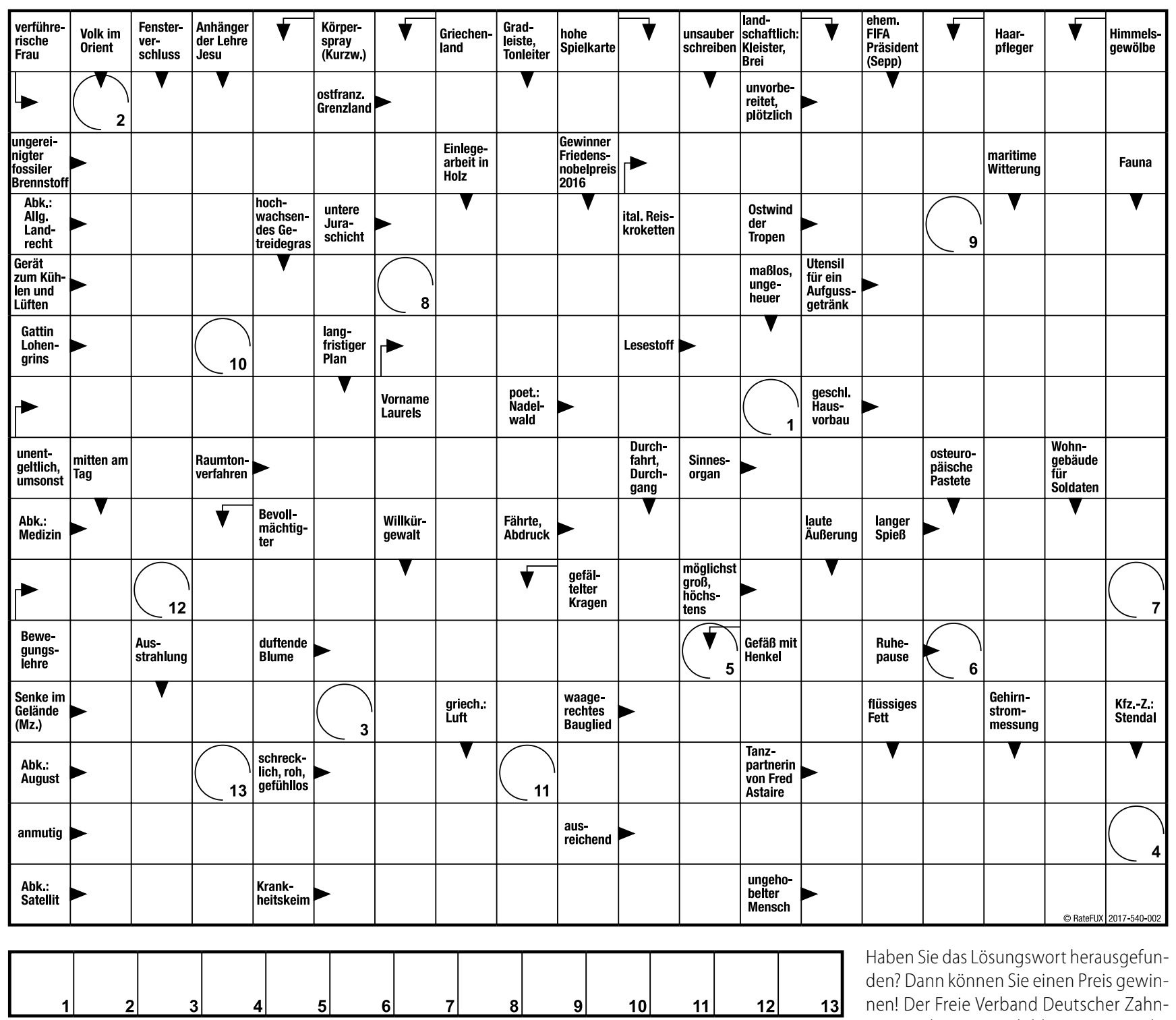

Haben Sie das Lösungswort herausgefunden? Dann können Sie einen Preis gewinnen! Der Freie Verband Deutscher Zahnärzte verlost ein Fortbildungsseminar der FVDZ akademie. Senden Sie das Lösungswort per Mail an raetsel@fvdz.de oder per

\title{
Angebohrt
}

Post an Freier Verband Deutscher Zahnärzte, Mallwitzstraße 16, 53177 Bonn. Einsendeschluss ist der 31. August 2017.

\section{Hohes Risiko}

Die Zahnärzte erklimmen ja statistisch gern höchste Höhen. So sollen, was das Gehalt angeht, Zahnmediziner ja ganz vorn mit dabei sein, heißt es oft. Und nun das: Der Beruf Zahnarzt ist auf Platz zwei der ungesündesten Jobs weltweit gelandet.

Für ihre Untersuchung wertete die US-Website I Fucking Love Science 974 Berufsgruppen nach ihrem Gesundheitsrisiko aus. Und da kamen Zahnärzte wegen des häufigen Kontakts mit Krankheiten, Infektionen und Strahlung und wegen der vielen Arbeit im Sitzen schlecht weg. Locker stachen sie sogar ZFAs und Zahntechniker aus. Den ungesündesten Job haben aber laut der Studie Dentalhygieniker. Bei der nächsten Gehaltsstatistik kann die Rede da schon fast von Schmerzensgeld sein.

\section{Enormer Pfusch}

Es soll ja (Vor-)Schulkinder geben, die sehnen sich geradezu nach einer ach so „coolen“ Zahnlücke: Lässt ein Wackelzahn sich gar zu lange Zeit, greift so mancher ABC-Schütze schon mal zum alten Trick mit der Türklinke.

Ziemlich vergriffen hat sich aber eine Mutter im US-Bundesstaat Utah, als die Milchzähne ihres Sohnes anscheinend nicht ausfallen wollten: Kurzum fuhr sie mit dem Siebenjährigen in den nächsten Walmart, erstand eine Handwerkerzange und versuchte gleich auf der Supermarkt-Toilette, ein paar Zähne zu ziehen. Allerdings saßen die doch noch zu fest, im Kiefer des Jungen blieben einige Wurzeln stecken. Dem laut schreienden „Patienten“ eilte ein Walmart-Angestellter zu Hilfe - und zeigte die Möchtegern-Zahnärztin an. 